\title{
Shadow Conditions and the Immeasurable Burden of Improvement
}

In Juntos, everything is a threat, that the program will be taken away. It's development done through fear.

CARLA, DIRECTOR OF A SMALL NONPROFIT FOR RURAL WOMEN AND

GIRLS'EMPOWERMENT.

On a wet and muddy day in Santa Ana District, a Juntos local manager summoned all Juntos recipients from the villages of Sonsonate and Bellavista to a meeting. The local manager called the meeting on behalf of a community worker from the state-run day-care program called Cuna Más. The day-care program was part of a broader attempt by the Ministry of Development and Social Inclusion to improve early childhood development in poor and extremely poor communities throughout rural Peru. The day care offered free child-minding services, which were provided by unpaid women in the community, and nutritious snacks and lunch for children aged six months to three years. Cuna Más had been operating in the area for less than a year, and the community worker was having difficulty convincing women to use it. ${ }^{.}$Sonsonate and Bellavista each had a Cuna Más day care, as did some neighboring villages. In Sonsonate, it was set up in the newly constructed municipal hall, a clean but cold and windowless concrete building. The day care in Sonsonate had problems recruiting mothers to use the services, but it was the day care in Bellavista that was really a problem for the community worker. The state had set up the Bellavista day care in a small building beside the local cemetery, and the women refused to take their children there because they said it frightened them.

The Juntos local manager, rather than the Cuna Más community worker, had called the meeting to make sure the mothers attended. It was widely understood among frontline state and NGO workers in both districts where I carried out research that meetings called by Juntos were far better attended, because women thought they had to attend in order to earn the cash incentive. This particular meeting was held at ten in the morning in a simple, bright room adjoining the local health post. A few posters advising women about birth control decorated the 
concrete walls, which had been painted a powdery yellow. Most of the mothers arrived late, having waited until the rain let up before descending the muddy hills. By the end of the meeting, approximately eighty women, many of them winding wool on tall palitos, were seated on long wooden benches and spilling out of the doorway and onto the grassy front courtyard. A few silent husbands were scattered throughout the crowd. The Juntos local manager and the Cuna Más community worker, both of whom were women, sat facing the mothers. They had sunglasses tucked into their fair hair and the badges of their respective government programs embroidered on their official vests: bright red for Juntos and bubblegum pink for Cuna Más. The following vignette from my field notes describes what I observed at the meeting.

The Cuna Más community worker stands at the front of the room and tells the Juntos recipients that they must leave their children under three years of age at the day care, regardless of whether or not the children cry. She says that perhaps the women might cry at first too, but afterward both mothers and children will become used to it. The crying, she says, is not an excuse. She tells the mothers that if they don't use the day care it will be taken away, and then maybe Juntos as well, because the ministry will think they obviously don't want social programs. Furthermore, after day care, children must go to kindergarten and then elementary school, and finally high school, whether they like it or not. The community worker tells the assembled mothers that they might as well accustom the children to being separated now, so that it is not hard for them to go to school. If not, it is only the mothers' fault if the children don't want to go to school. There is no one else to blame.

The mothers have been seated the entire time, silently listening to the lecture; some of them are drifting into sleep or staring into the distance. Finally, the community worker asks the women if they have any questions or comments about the day care, because she knows that "things aren't always rosy" and tells them not to be afraid. This is again followed by silence, until one mother asks how old the baby must be to go to the day care. The community worker explains that women should begin taking their babies to the day care at six months of age, so long as the mother sends breast milk with the baby, and all children should attend until aged thirty months.

Many of the women begin chatting among themselves, and the Juntos local manager instructs them sternly to leave their "gossip" at home, that meetings are not the place for it. A Mother Leader turns around from her position on a front bench and yells at the other women to be quiet. The local manager takes a turn speaking. She tells the mothers that as Juntos recipients they are obligated to take their children under three years of age to the day care. She reminds them of "the objectives of the Ministry of Development and Social Inclusion," which are "to create human capital" and "achieve the eradication of poverty and extreme poverty." She reminds them that they receive the two hundred soles not because "the government is really nice," that the cash is contingent upon fulfillment of the coresponsibilitiesshe stresses this word. She then enters into a lengthy lecture about education, health, and MIDIS. Many of the women are looking elsewhere; they appear bored. A mother seated near the door named Gloria says that she refuses to take her son to 
the day care, because he cries too much. She is sorry, but she absolutely refuses. The local manager replies that she doesn't have a choice, she must leave her son there, and that all Juntos mothers must.

Both the Cuna Más community worker and the Juntos local manager told the mothers present at the meeting that their coresponsibilities as Juntos recipients included use of the day care. This was not true. The state did not require Juntos mothers to use the day care-at least not officially. Nevertheless, the Juntos local manager threw the weight of her authority behind the Cuna Más worker's fabricated assertion that MIDIS would take Juntos away if the mothers refused to use the day care. While the local manager did not have the institutional mandate to monitor women's compliance in using the day care, she did expect that following the meeting the mothers would amend their behavior and begin to use it.

In my observations I frequently saw local managers using their influence and threats of program suspension to get Juntos mothers to do things that were not officially mandated. This practice was not particular to Peru. Research in Mexico showed that mothers in the world's second-largest CCT program were required to do collective community work called faenas (González de la Rocha 2006, 129; Saucedo-Delgado 2011). This work included, among other activities, collecting rubbish, cleaning the school, and maintaining gardens. Development experts there suggested that the unpaid work was "voluntary," but mothers complained that the work was undignified and took them away from tasks they would rather be doing, including paid work (Rivero 2002, cited in Molyneux 2006, 435). To my knowledge, what follows is the most thorough and data-rich examination of what we should make of such events currently available in the peer-reviewed literature.

Ethnographers of development have suggested that policy is not made in the tidy offices of experts, but that it becomes what it is during implementation (Mosse 2005). Bearing this in mind, in the pages that follow I describe and analyze what happened when the implementation of Juntos collided with the needs, desires, and influence of a variety of actors within and outside of the program. Research on the impacts of CCTs that mentions these "additional" activities tends gloss over them, as though they were insignificant. ${ }^{2}$ The unintended consequences of women's additional labor may not be apparent at all in evaluations that focus on the effectiveness of CCTs at achieving children's health and education uptake. When these activities are viewed from the women's perspective, however, they appear worthy of sustained and critical attention.

\section{SHADOW CONDITIONS}

When I asked Juntos mothers what they had to do to earn the cash incentive, they told me that they had to take their children to school and health appointments. They also told me that they had to do a whole bunch of other things. These included 


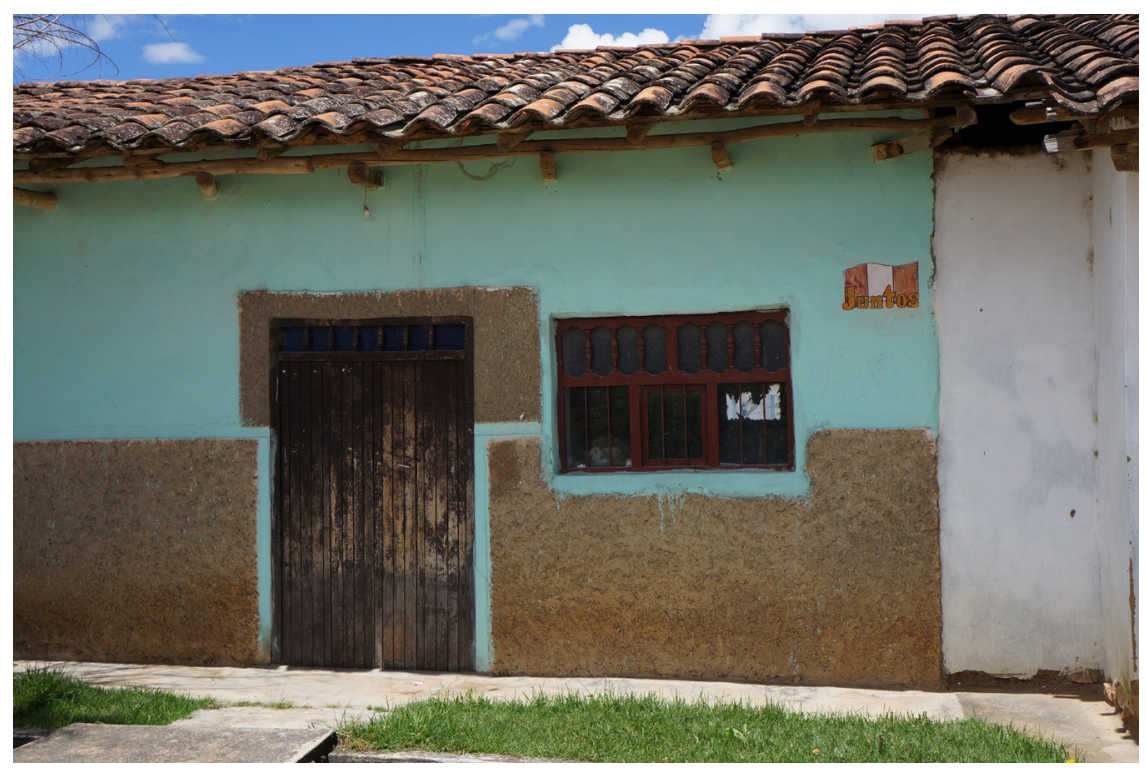

FIGURE 16. Shadow condition 1: A painted Juntos flag signals that recipients of social assistance live here. Photo by the author.

a variable combination of the following: attending meetings; growing a garden (biohuerta); giving birth in a health clinic; keeping hygiene instruments (toothbrush, soap) organized; cooking for the school lunch program, Qali Warma; having a latrine; using the state day care, Cuna Más; participating in political parades and parades for local cultural events; painting the Juntos flag on the outside of their house (figure 16); contributing to the medical costs of a neighbor's broken leg; using a cocina mejorada (smokeless stove); attending hygiene trainings; participating in a regional cooking fair; attending a literacy workshop, and "doing whatever the [local manager] tells me to."3

In all of the interviews I conducted, women named at least two of these extra tasks; on average they named four or five. I also observed mothers in their roles as Juntos recipients participate in microproductive projects such as raising cuyes (guinea pigs) and producing handicrafts (figure 17). In Cajamarca city I once observed throngs of women, all wearing red hats, marching unenthusiastically through the streets behind banners advertising the incumbent regional governor's political party. A local NGO worker later told me the women were Juntos recipients that the governor's office had brought in on buses from rural villages. ${ }^{4}$

I refer to these additional tasks as shadow conditions (Cookson 2016). ${ }^{5}$ I use the term shadow to evoke the idea that the activities were not present in the tangible spaces of policy. They were not featured on the Juntos website or in the manuals 


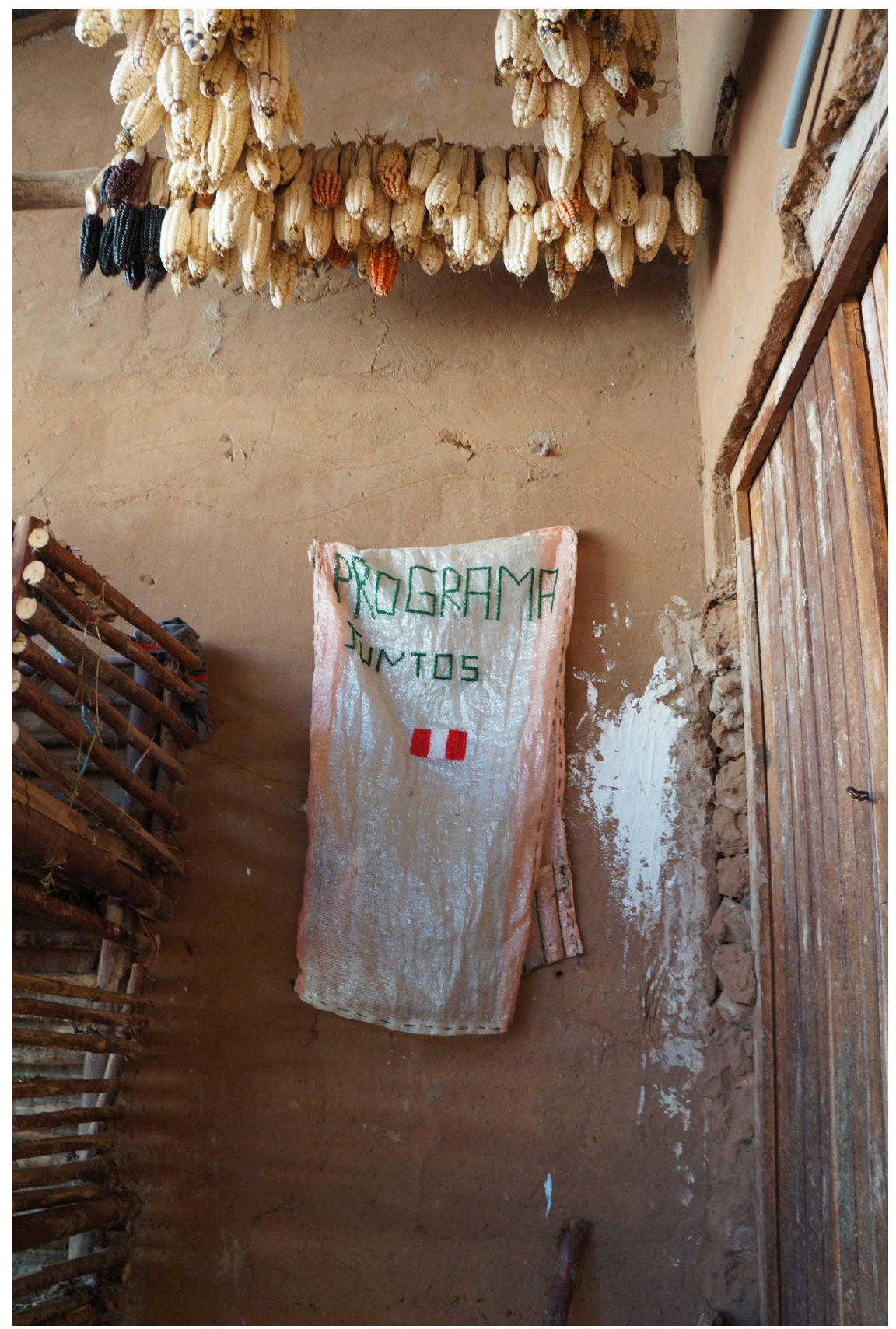

FIGURE 17. Shadow condition 2: Producing handicrafts. Photo by the author. 
used to train local managers. They were not listed on the verification-of-coresponsibility forms that Juntos used to monitor women's compliance with program conditions. From Lima, these activities were hard to see. Shadow conditions lurked behind and alongside those conditions that development experts insist are vital for the poor to meet in order to lift themselves out of poverty. While shadow conditions were shadowy by all official accounts, in the places where Juntos was implemented they were highly visible.

From the perspective of Juntos mothers, conditions were conditions. The conditions requiring women to take their children to school and health appointments were enforced and monitored by local managers, who often acted in coordination with school and health clinic staff. Shadow conditions were similar: local managers often worked in collaboration with other local authorities-including health and education staff, government bureaucrats and politicians, and employees from NGOs and other state social programs-to implement shadow conditions. Shadow conditions were thematically similar, too. Many of the activities were related to improving the health and education of children or sometimes the women themselves. Others benefited the household or local economies. Juntos's tagline was: "Working together so that our children live better than we do." And many of the shadow conditions fit under this banner. With the concept of shadow conditions in place, I'd like to elaborate on its meaning and significance with a few more practical examples.

Two commonly mentioned shadow conditions were having a latrine and keeping a tidy house. Several Juntos recipients had a handmade organizer in which they kept the family members' toothbrushes and soap (figure 18). ${ }^{6}$ This was frequently hung on the wall of the outdoor sitting area, where families would receive visitors. Juntos mother Marisela told me, while we sat at a large wooden table that was covered in her children's homework, about having to meet conditions related to household hygiene. She had just finished telling me about the garden that Juntos required her to maintain, and I had asked if there was anything else she had to do.

TC: And what else [in addition to keeping gardens] do you have to do to be in the [Juntos] program?

Marisela: Well, for the program we also had to build a lavatory [baño].

TC: A lavatory? What do you mean?

Marisela: In the garden there is a latrine [rincón de aseo], and a place to keep the children's toothbrushes so they brush their teeth. And also we have to make sure that our children have their things, that they aren't missing any school supplies, and that they are nice and clean. That's what the local manager tells us.

Mothers frequently told me that the local managers entered their homes, uninvited, and "checked" to make sure that the house was "tidy." The women were unsure of 


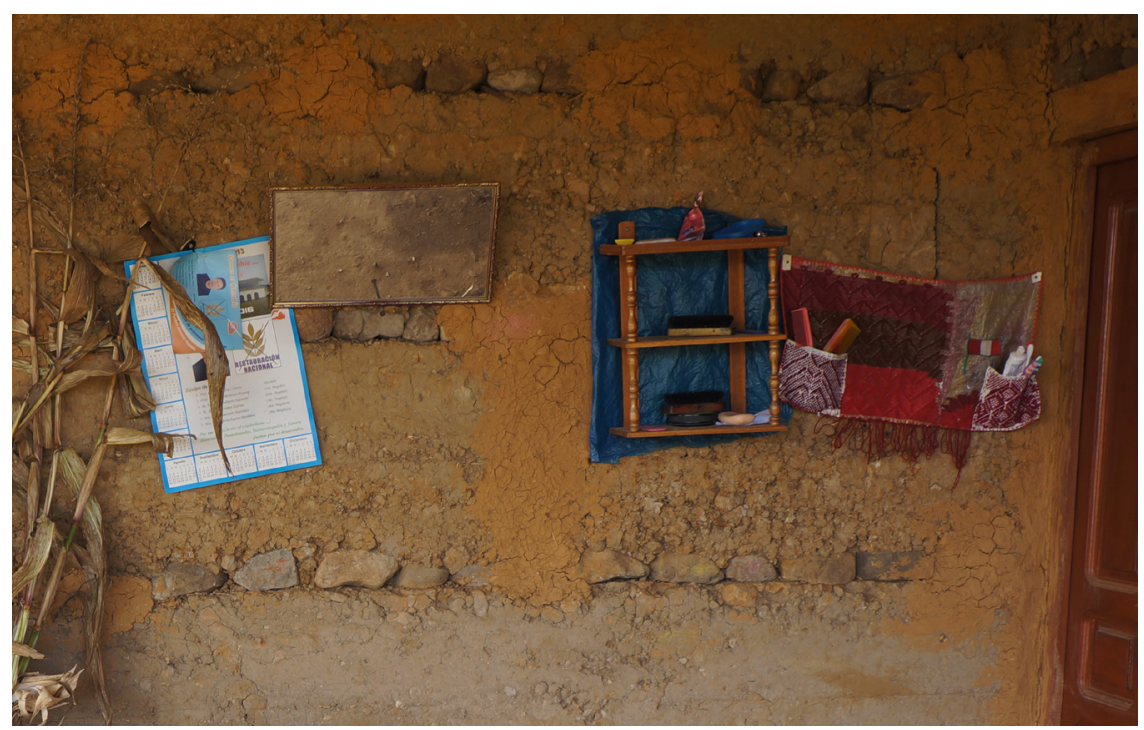

FIGURE 18. Shadow condition 3: Keeping hygiene instruments organized (note the Juntos flag). Photo by the author.

the schedule upon which the monitoring would occur. When I asked mothers what tidy meant, they usually said that it meant "not dirty," and that they housed their small animals outside of the sleeping quarters. This was not always a simple task, because many houses consisted of only one or two rooms. Women raised small animals like cuyes, chickens, and rabbits to feed their families or sell at the market. They were valuable and had to be protected against cold, loss, and theft.

Some of the conditions, like keeping a tidy house and maintaining lavatories and latrines, were to an extent aligned with Juntos's mission to improve children's health. Other shadow conditions, like participating in parades and fairs, seemed further removed from Juntos's stated aims.' Santos, a slight, gentle woman, had been receiving the Juntos payment for less than a year. She became a Juntos recipient shortly after taking over care of her five-year-old grandson. His mother's new partner had "problems" with the boy, and Santos had agreed to raise him. Santos and her husband had previously migrated seasonally to the coast to harvest corn and rice, poorly paid work that was extremely physically demanding. Now that her grandson was of school age, Santos and her husband could no longer migrate for work, and other work was scarce. So they moved to Sonsonate from Cajamarca city in order to meet Juntos's rural eligibility requirements. In Sonsonate they rented a small, humble home with packed-earth floors on someone else's plot of land. When I interviewed Santos, she explained what it was like when she first became a Juntos recipient. One of the things she talked about was participating in 
a year's-end celebration organized by the mayor. Juntos local managers asked the Juntos mothers to prepare local dishes and showcase the weaving they had done as part of an initiative implemented in conjunction with an NGO. This is what Santos said:

Santos: The [local managers] also asked us to go to an activity the [Juntos] program organizes for the year's end. They wanted us all to be there, all wearing the same thing, a white blouse. I went to that too.

TC: What was the activity for?

Santos: They said it was a party. As I had just started in the program, I still didn't know much. They said we couldn't just go like this [indicates current clothing]; I had to wear [a white blouse].

On another occasion, at a Juntos meeting in the district of Labaconas, I observed a local manager implore a roomful of mostly reluctant mothers to march in the forthcoming carnival parade, which I later learned was sponsored by the district governor. The local manager capitalized on the enthusiasm of a few husbands present within the group to pressure the women into participating. By the end of the meeting the women had begrudgingly agreed. Once it was determined that the women would march, the mother seated next to me confided that the women didn't want to participate because there was likely to be excessive drinking, and if they went to the carnival, who would watch over the children?

All conditions, including shadow conditions, functioned via threat of suspension. Women complied with shadow conditions because they thought they could be suspended from the program if they did not. Threat of suspension was especially effective because what was actually required of Juntos mothers in order to receive the payment was not clear to them. I did not speak with a single Juntos recipient whose understanding of what she was supposed to do to earn the incentive matched what the state actually required her to do. Shadow conditions and official conditions blended seamlessly into one another, and none of them were activities that they were entitled to refuse. Suniva had been in the Juntos program for five years when I interviewed her and her sister, who was also a Juntos recipient. When I asked about program conditions, Suniva told me about the threats that women received from the local managers:

TC: And what do you have to do to stay in the Juntos program?

Suniva: Do what they tell us. Plant gardens, have vegetables, all this. Because if not, they say that they'll kick us out of the program.... They suspend us. Like that, they've said it to us.

The threats that local managers made were effective, but they did not always make sense to the mothers. Gardens were a good example of this. Yesenia, who had been in the Juntos program since it first arrived in Bellavista, voiced a common 
complaint among mothers. She said that Juntos made the mothers maintain gardens, but she, like the other mothers, didn't have access to "even one minute of irrigation a day." As a result, she was able to grow only certain plants such as eggplant and Andean tomato, and felt frustrated at what she perceived to be an unreasonable request. Juntos mother Marisela, too, was frustrated: "Sometimes we can't do [what the local manager asks], and she says things like: 'You all have to do this or I'll suspend you'-for example, with the gardens. But in this season there isn't any water; there's a drought, you see. There isn't any at all, so what are we going to water [the garden with], when there isn't even water to drink? Never mind [for the garden]."

Keeping gardens was not a reasonable request, given the infrastructure the mothers had at their disposal. The communities of Bellavista and Sonsonate, like others in the region, suffered from a water shortage and, as a result, did not have continuous access to irrigation. In order to equitably mange the insufficient water supply, members of both communities decided on a schedule for water use. As a result, women had a narrow, predetermined window of time when irrigation was available to them, and they made careful use of that schedule. ${ }^{8}$ On many occasions I observed women staying home to await their turn to fill a water container or irrigate their small plot of land. To be sure, local managers did not live in the same communities as the mothers they managed, and so they did not experience the water shortages firsthand. Gardens might have seemed like an excellent idea, and one that was aligned with promoting children's good health. But these women had been contending with the water shortage long before Juntos arrived in their communities - which is to say that the local managers should have been aware of the mothers' particular constraints.

Access to resources and the intended benefits of the activities aside, shadow conditions like gardens, latrines, and participation in parades underscore the coercive potential of conditionality. The threats local managers used were effective. Shadow conditions, like the health and education conditions, were not couched in the language of volunteerism, choice, or self-improvement. Mothers understood that the cash incentive was attached to conditions, and the local manager would monitor whether those conditions were met.

\section{THE COERCIVE POWER OF INCENTIVES}

In chapter 3, I noted that there were at least two reasons why women complied with program conditions even when the quality of services was inadequate and when doing so generated costs for the mothers themselves. The first of these reasons was the material support that the cash transfer offered poor households. Juntos provided mothers who had few other reasonable economic opportunities with "a little bit of help" in meeting the material needs of their families. The second motivating factor behind women's compliance was the disciplining power of "responsible 
motherhood" narratives that circulated through policy language, through local managers' appeals for women's compliance, and through the language women used when describing one another's behavior. The need for material support and notions of responsible motherhood also disciplined women's compliance with an extensive list of shadow conditions. Yet given that shadow conditions imposed additional demands on their time and labor and compromised their dignity, it is worth revisiting the question of why women comply.

When I asked local managers why they thought women complied with shadow conditions, they told me the reason was simple: the mothers wanted the cash. For instance, "[Juntos mothers] think that 'if I miss a meeting they'll suspend me,' if I don't do this thing they'll suspend me.' And because they've become accustomed to their [two hundred soles every two months] . . . they are afraid that they'll be cut off, that they won't be paid." In one sense, we could say that mothers were materially accustomed to the CCT and so were willing to comply with extra tasks in order to earn the money. Yet this was not the full story. Shadow conditions illustrate another driver of women's compliance that has to do with women being socially accustomed, or disciplined. This was explained to me by the local managers' direct supervisor. In an interview, she emphasized the power of influence that local managers, as arbitrators of the incentive, had over the women they managed: "Unfortunately, because it gives out money, Juntos is very powerful. It has a lot of power because it gives out money. If a local manager says to the mothers, 'All of you must come down the hill tomorrow at ten at night', all the mothers will come down the hill. They'll come down the hill because they know that they're conditioned [están condicionadas]."

To suggest that Juntos mothers "están condicionadas" could mean "mothers are required"-because the money was attached to conditions. Or, it could mean "the mothers are conditioned" in the sense that they were socially conditioned, or habituated, to respond in a particular way. It is worth examining the ambiguity of this phrasing. On one hand, women were required to engage in a set of activities in order to earn the cash payment. In a technical sense, that was how the incentive worked. On the other hand, figures of authority made a habit of using threats of suspension to discipline women's choices and behaviors, and this easily extended beyond the bounds of "official" policy. Whereas the cash itself provided a material impetus for running down the hill, the CCT also had a deeply coercive social element. To be clear, saying that women were habituated or disciplined was not to say that Juntos beneficiaries acted without agency. Rather, Juntos organized women's experiences in such a way that the reasonable thing to do was to run down the hill at ten o'clock.

The coercive power of Juntos - and its expansive quality-was illustrated in the weeks that followed the joint Juntos and Cuna Más meeting that opened this chapter. After the meeting, mothers spoke about having to take their young children to the day care despite not wanting to. At two focus groups with Juntos mothers, half 
of the group said they cried when they had to take their children to the day care. According to these women, it was not right that Juntos required them to do so, but they did it anyway. They said that using the day care took time away from other tasks because they had to go up the hill to get there. Some mothers who were afraid to leave their children at the day care chose to neglect their other tasks altogether and instead spent the day sitting outside the facility. ${ }^{9}$ Juntos recipient Graciela said that she brought her baby to the day care only because Juntos obligated her to and she did not want to be suspended from the program, which was a fear her husband also shared.

Mothers' fear of suspension was sustained by the total fog surrounding what was and was not suspension-worthy, and by the power that local managers had to manipulate this fog. Local managers spent a great deal of time in a data collection exercise that was imprecise and required a good deal of discretionary decisionmaking. They were in a position to suspend a program user by error-if they had imperfect information-or by choice. When a local manager was unable to locate a medical history or encountered illegible information, they had the power to determine whether to register that particular Juntos mother as compliant or noncompliant, which determined whether that household would be suspended from the program or would continue receiving the cash transfer.

Such decisions were influenced by the personal relationships between the local manager and the mother. Like in CCT programs elsewhere, I observed that local managers made decisions that were colored by their perceptions of CCT beneficiaries' deservingness (Hossain 2010). On several occasions I watched that play out favorably for mothers. For instance, when Juntos mother Sunilda had not taken her daughter to all of the required health appointments (she missed the last one), she explained to her local manager that the nurse had told her not to bother coming. Instead of recording that Sunilda hadn't met the conditions, the local manager told Sunilda that shed let it go this time. She did issue a warning-if her children did not attend checkups in future, she would be kicked out of the program.

On another occasion, I observed a local manager accept bags of freshly harvested corn from a Juntos family's plot after they asked her to overlook the fact that their seventeen-year-old son had migrated elsewhere to work, despite not having graduated high school. This would normally be cause for suspension, but in this instance the local manager agreed "to look into it." I also witnessed local managers castigate women whose behavior they deemed irresponsible. The same local manager who accepted the corn chastised a Juntos recipient later the same day for how she treated her elderly mother, saying that she had heard from other community members about the "disrespectful behavior." It was unclear to the mothers as well as to me how the local managers determined what was worthy of suspension.

Women's fears were not totally unfounded. During an interview, local manager Lina explained to me that local managers were responsible for filling out the verification-of-coresponsibility forms, and "[the forms] are money for the mothers." 
Local managers ultimately determined whether a mother would receive the cash payment. This granted them a great deal of power over the women they managed. The local managers' direct supervisor told me in an interview that she believed the local managers should not have the opportunity to act "as judge and jury," granting or withholding the cash transfer according to personal discretion. She continued, saying, "They can do this, at the moment it is permissible to do it." The mothers were well aware of this dynamic and acted accordingly.

Narratives of responsible motherhood were at work in disciplining women's compliance with shadow conditions, too, and these converged with the lack of clarity and the threats of suspension that frightened mothers into complying. While half of the focus group I previously mentioned said that they cried when they had to take their children to the day care, the other half said that Cuna Más allowed them to participate in tasks other than child care, and that Cuna Más provided food. This was especially helpful because, according to the mothers, their children were "malnourished." Looking around at the plump babies, I found this a curious response. I also had become accustomed to hearing mothers repeat, verbatim, things that local managers often told them. Mostly these things related to the educational and health deficiencies of their children and to the merits of responsible motherhood. Women also heard these things from the many other social program workers and NGO employees who cycled through their villages, identifying deficiencies and lecturing women on how they could be improved. Women took up these narratives, referencing their self-improvement and identifying how they had previously been "irresponsible" in the ways they cared for their children and households.

I observed an illustrative example of this when local managers were monitoring women's conditions at a health clinic. Juntos mother Apollonia was being interrogated by her local manager about whether her children had attended their most recent health check. Apollonia's response, "Yes, miss, I don't neglect my children anymore," obviously indicated that she had been told previously that her behavior was neglectful. Juntos mother Ninón, who was chronically ill, told me about the ways local managers taught her to alter her domestic and hygiene habits: "[The local managers] teach us to keep ourselves a little tidier. You see, in the countryside we live all together with our small animals, and [the local managers] always tell us that we should live separately. To keep ourselves clean. It is nice to learn. In the campo we live how we live, and so they guide us. We learn. It's much better."

Women were constantly being "guided" by their local managers to mother more responsibly and to raise more professional children. When they did so, mothers commended one another's improvements. During a focus group, a very poor woman named Soledad, mother to two small girls, arrived late. As Soledad quietly took her seat, eyes averted, she was proudly introduced by a kindly Mother Leader, who said that Soledad had recently started taking her youngest daughter to the Cuna Más day care. According to the Mother Leader, Soledad wanted to take better care of her 
children, commenting that "before, they were dirty, as was she." Thankfully, Soledad had decided to "make a change." Narratives about good or responsible motherhood were powerful; they disciplined women's behavior similarly to, if not more extensively than, other social programs (Molyneux 2006; Bradshaw 2008). Framing women's choices in terms of responsible motherhood "conditioned" women to walk and wait for poor-quality health services. These narratives extended well outside the bounds of "official" policy in the sense that local managers and other authorities often called upon mothers to meet shadow conditions in their roles "as mothers."

The only mother present at the focus group who did not use the day care was Eufemia. She had decided not to comply with the local manager's demand, because her husband told her that the program "is more trouble than it's worth." While Eufemia's decision to resist the local manager's pressure was not representative of broader observations, it suggested the limits of Juntos's coercive power. Whether women complied-and on what terms - was shaped by women's agency, husbands' decision-making power, and analyses of the relative costs and benefits. Critical development studies scholars suggest that power is never only unidirectional, and even those at the margins have opportunities to resist (Scott 1985; Rankin 2001; Li 2007). This important point raises questions about what recourse CCT recipients had in the face of poor-quality services, abusive behavior, or unreasonable shadow conditions.

\section{CONDITIONS FOR COMPLAINT}

Juntos offered rural mothers the virtual equivalent of a complaint box. Unhappy women had the option of filing an official complaint online or by telephone. In theory, this system allowed Paloma, who was concerned about the teacher shortage, or Felisa, who couldn't access adequate health care at her nearest clinic, to register their concerns directly with Juntos's head office in Lima. In practice, this system was rife with absurdity. One consequence of historic underinvestment in education services in rural Peru is high female illiteracy. This enormous barrier, combined with the near total absence of Internet connection, made the option to file a complaint online almost laughable. The option to file a complaint by telephone was perhaps more reasonable but raised the question of how women were to locate the number for the hotline-I found it online. If the complaint in question concerned a local manager or health or education professional, it was highly improbably that the mother would seek to obtain the hotline number from any of them!

The third option available was to file a complaint in person at the Juntos regional office. However, for Paloma this would involve the time and financial cost of a two-hour journey by combi, and for Grimalda, up to six hours by foot and two or three combi rides, depending upon the availability of cars that day. This journey would have to be repeated on the way back, too. Another matter altogether was whether the complaint would actually make it to the relevant officials. On several 
occasions, I witnessed the security guard stationed outside the Juntos office in Cajamarca city refuse entry to campesinas who had traveled there.

Some researchers have suggested that CCTs open up new opportunities for citizens' engagement with the state, including the opportunity to complain about the poor quality of services (Hickey 2010; Hossain 2010). How effective these opportunities are is questionable. Juntos mothers' complaints, especially to one another and even sometimes to local managers, evidence low-income women's agency under constrained circumstances. However, the effectiveness of complaining is limited when you live isolated from the places where complaints can be effectively translated into meaningful improvements (Corbridge 2007, 197). The complaint system offered to rural mothers also raises the broader issue of transparency and accountability in program implementation. Women were unaware that institutional birth and participation in parades were not actual policy requirements-so why would they complain about them? Women's compliance was understandable when read against the combined factors presented here: intense social pressure to be a "responsible" mother, limited livelihood resources, and unclear information regarding what conditions Juntos recipients were actually required to meet.

\section{INSTITUTIONAL BIRTH}

While trying to maintain a garden might be futile and irritating, participation in a parade stigmatizing, and taking infants to day care emotionally stressful, the consequences of compliance with other shadow conditions had riskier consequences. The parto institucional, which meant "to give birth in a health center" (henceforth "institutional birth"), was one example of this. The subject of institutional birth came up frequently in my interviews and observations. The following vignette from my field notes describes a scene that took place at a Juntos meeting at the municipal hall in Labaconas. ${ }^{10}$ The two local managers who worked in the district had summoned Mother Leaders and invited health staff and local government, so that everyone could be "on the same page" regarding what was required of the various actors in the forthcoming year insofar as Juntos was concerned. Whether Juntos recipients were required to have an institutional birth was one of the topics discussed.

Quietly seated Juntos mothers have now been at the meeting forty-five minutes. In a raised voice, the female local manager insists that women give birth in a health facility, rather than at home: "Look-institutional births are obligatory! Let's be clear about this!" The mothers are being lectured like children who have misbehaved. A young female nurse begins to talk about why institutional birth is important. Contradicting the local manager, she says that she has received many complaints from women about the perceived requirement to have an institutional birth, and that "institutional births are not obligatory." However, she says, they "are better," and "what would happen if something went wrong at home?" The male local manager 
interrupts to say that they will "sanction" and "suspend" those mothers who do not give birth at a health facility. He continues by saying that pregnant women must report when they are pregnant, and that Mother Leaders must ask the women and tell the local managers.

A mother named Janina from Comabamba village speaks out: "I am very sorry but I live very far away, so this is impossible-how would I ever be able to get there?" Other mothers voice their agreement. The young nurse responds saying they must try, as she has seen many maternal deaths. She says that she is frustrated by having to go to women's houses at nine, ten, eleven o'clock at night and not be allowed to attend a birth because the sister or mother-in-law is assisting. Near the point of yelling, she says that when she touches women giving birth "they protest, but not when the midwife does it! She can do whatever!" as she imitates gently touching them, and then switches to the women's supposed silence when a midwife uses her knee along the lower back to assist the labor. Many of the mothers laugh, but the nurse does not. She replies angrily, "You don't let me work!" The female local manager interjects that the mothers should not do it for the two hundred soles [Juntos cash transfer] but for their "own well-being."

At the meeting, local managers told Juntos recipients that institutional birth was obligatory, threatened women with suspension, and enlisted the help of Mother Leaders in monitoring compliance. Other accounts I collected described women having been denied their newborns' birth certificates by health staff after home births unless they paid the health staff a fine. This particular abuse of power came up during informal discussions with Juntos women and was also reported by Maria, a nurse running a Cajamarca-based not-for-profit reproductive health clinic. She recounted that many Juntos mothers sought out her clinic for birth certificates after being refused at public institutions. Maria always provided the new mothers with the documents, free of charge.

At the Sonsonate clinic in Santa Ana District as well, the nurse told Juntos recipients that institutional birth was obligatory: "Regarding family planning, the Juntos program doesn't demand much of the mothers. But for the expectant mother, yes. They have to come for monthly checkups, and the birth has to be in a hospital. They have to give birth in a hospital or clinic. They can't give birth at home." She went on to relate that some women refused institutional birth, especially those whose prior births took place at home: "[The local managers] still haven't convinced 100 percent [of the women].... [T] here are mothers that already have three, four, five children, and they don't accept it, that they have to give birth at the clinic. They still give birth in their houses." ${ }^{12}$

When I asked Juntos recipients if institutional birth was compulsory, their responses were mixed. Most of the time institutional birth was identified as a program condition; however, women whose children were older tended to respond that the institutional birth was optional, and others said they weren't sure. ${ }^{13}$ The lack of clarity around the issue is understandable. Local managers often said one 
thing and then demanded another; and inconsistencies between local managers were rife. Health staff also operated with erroneous information about what Juntos actually required; this finding is consistent with evidence from studies in other regions where Juntos intervened (Díaz et al. 2008). ${ }^{14}$

Mothers offered a number of insights as to why some women "still [gave] birth in their houses," and these provided perspective on why the shadow condition requiring institutional birth was particularly insidious. In chapter 3, I discussed how rural women were frequently subject to discrimination and abuse when they interacted with the health and education systems on behalf of their children. Mothers also had unpleasant experiences when they accessed maternal care, which understandably shaped their preferences. Women described giving birth at home as more comfortable. Juntos mother Pepita explained to me that this was "because you have the help of your mother and husband"; at the clinic, the nurses are "brusque and you must lie down." Unlike many of the other clinics and health posts I visited, the public health facility in Sonsonate was very clean, which I associated with its university affiliation. The post was staffed by a technician, as well as a nurse who had worked there for many years. The nurse was organized and punctual, although some women in the community thought that she attended only "who she wanted, when she wanted" (Custodia, Juntos recipient).

While not all health staff treated women poorly, the generalized sense that women would not be treated fairly or with dignity if they went to the clinic spoke to deep-seated issues in the health system. In Peru, discrimination against campesinas and indigenous women is common and historically rooted in health policy and service delivery (Ewig 2010; Oliart 2003). Women, who are more likely than men to retain markers of ethnicity such as dress and language (de la Cadena 1992), commonly experience culturally insensitive and discriminatory treatment by urban white or mestizo health professionals (Ewig 2010). ${ }^{15}$ Juntos mothers connected the poor treatment they received from health staff to the social position that poor campesinas occupied. Juntos mother Paloma explained to me that the poor treatment was because "we are humble people." Women's experiences of discrimination raise serious questions about whether incentives and conditions would be needed if the services were adequate and dignified.

The shadow condition requiring institutional birth was also harmful because of the underresourced environment in which it was implemented. As I discussed earlier, access to care was limited and unreliable. For an expectant woman, giving birth at a health clinic or post made sense if she lived within a short distance of it, had access to safe and reliable transportation, and was certain that when she arrived she would find it open and adequately staffed. This was not the reality for most of the women in my research. For many women in rural Peru, deciding to deliver a baby at a clinic entailed a journey of several hours on foot, and the very real risk that the clinic would not be open or would not be staffed by a qualified health professional. 
I bore witness to how this scenario could play out on an otherwise quiet afternoon in February. I had accompanied a local manager in the district capital as he tracked down Juntos mothers who had recently given birth in order to collect their newborns' birth certificates. We had just returned from a failed attempt to speak with the nurse at a health facility in another village-the clinic had been closed, again. The furious local manager suggested that we would try again the following day, and so we returned to the district capital. We were chatting with a few municipal workers in the central plaza when a small commotion broke out. The social development director came running from the municipal hall speaking frantically into his mobile phone. Upon encountering a colleague, he related that a mother named Trinada was in labor in a village far away, and the district's one ambulance would not start. The two men surmised that the battery was dead and noted aloud that there wasn't a driver, anyway. Considering this, they tried to figure out how to get Trinada to the health facility. Despite the fact that the facility was located over an hour's walk away, the two men decided that she would have to make the descent. On our way to lunch, the local manager informed me that women often walked to the clinic to give birth, as there were few roads.

Upon further inquiry at the municipality, I discovered that the ambulance battery was routinely dead. In fact, the ambulance had not been functioning for the past year. Later that afternoon, another mother went into labor in a village located three hours away by foot. In her case, the social development director traveled on a municipal dirt bike to bring her down to the clinic. As illustrated earlier, if a mother decided to try to reach a clinic while in labor and were to find it open, she might have to confront discriminatory attitudes and practices exhibited by the health staff in the community meeting. In fact, she might have to receive care from the same health worker who had mocked women's labor pain at the meeting.

To be sure, many governments and global health and development experts have worked hard to successfully reduce the rates of maternal mortality by increasing the number of women who give birth in clinics and hospitals rather than at home. Yet pursuing institutional birth is safe only when facilities are sufficiently accessible, and it is reasonable only when women can expect to be attended in a dignified and caring manner. The fact that some women walk hours over rough terrain while in labor for fear that authorities will strip their families of social support is a grievous injustice.

\section{SHADOW CONDITIONS: WELL-INTENTIONED}

DISTRACTIONS?

Juntos headquarters in Lima did not require or monitor women's participation in parades, where they stored their toothbrushes, or whether they maintained gardens full of leafy greens. Why did local managers? When Juntos was first implemented in 2006, activities like these were institutionally endorsed because experts 
in Lima viewed them as "complementary" to the program. ${ }^{16}$ Local managers carried out a variety of activities in conjunction with regional government and civil society in the communities where they worked (Vargas Valente 2010, 28). ${ }^{17}$ Mothers were expected to participate in the activities, but Lima did not require that their participation be monitored. In chapter 2, I discussed the institutional efforts to streamline Juntos's focus so that it enforced and monitored a narrow set of health and education conditions when Juntos was transferred to MIDIS. According to my interviews with experts in Lima, it was at that point that Juntos leadership decided that the program would no longer promote complementary activities. ${ }^{18}$

Yet time spent in the communities where Juntos was implemented revealed that many of these activities persist. For example, the gardens that mothers attempted to maintain formed part of a then-defunct initiative coordinated by Juntos and an NGO to improve household nutrition (Arroyo 2010). Juntos headquarters in Lima may no longer have supported the garden project, but women's accounts indicated that they believed tending the garden was yet another of the conditions they had to meet in order to receive the cash transfer.

Development experts at MIDIS and Juntos perceived shadow conditions as well-intentioned distractions from Juntos's mission. During interviews, I raised the issue of the extra tasks, expecting the revelation to come as a surprise. Policy makers and program administrators were, however, well aware of the practice. Some expressed the view that assigning women extra work was unfair, but they attributed shadow conditions to the good intentions of local managers, suggesting that a local manager's professional training determined the theme and endurance of the activities. For instance, one high-level expert told me that "if [the local manager] is a health worker they will be interested in health, that if it is someone specialized in agriculture they'll want to do projects in that." My observations indicated that while there may have been some correlation between a local manager's previous job and what she or he liked to see the mothers do, in fact shadow conditions extended well beyond professional interests. For instance, professional interests would not explain why a local manager trained as a teacher had women raising guinea pigs, participating in reproductive health training, marching in a carnival parade, and giving birth in hospitals.

Another high-level expert explained shadow conditions as follows, softly pounding her desk with her fist for emphasis: "Really great initiatives, all of these. But not a single one was part of the program; they all depended on the goodwill of the local manager. And they took time away from [the mother] fulfilling the program's objective [pounds fist on desk]." She continued: "The [Juntos] program has to report results to the country in terms of how many boys and girls have improved their health and have completed school attendance [pounds fist on desk]. . . . Juntos personnel have to dedicate themselves to what they are supposed to dedicate themselves, which is verifying that children are going to health and education services [pounds fist on desk]." While this perspective on shadow 
conditions may well have been valid in terms of what policy makers intended for Juntos, it missed a key point. Shadow conditions were not simply a series of distracting add-ons. Instead, shadow conditions were the direct result of making the cash transfer conditional.

\section{THE MAKING OF SHADOW CONDITIONS}

When power operates at a distance, people are not necessarily aware of how their conduct is being conducted or why, so the question of consent does not arise. TANIA M. LI, THE WILL TO IMPROVE, 2007

In contrast with the view from Lima, the view from the villages beyond Cajamarca city revealed that shadow conditions were a durable feature of conditional aid. In fact, they are liable to arise as a consequence of giving bureaucrats impossibly difficult jobs and, at the same time, remarkable power over poor women. The previous chapters have illustrated how local managers relied on mothers to walk and wait, to manage up, and to act as their "eyes and ears" in order to successfully implement Juntos. In addition to depending on mothers, local managers also relied on other local authorities in order to get their work done. Local managers needed places to sleep when they were in the field; sometimes this meant renting a room in a boardinghouse, but in more isolated villages they relied on health staff to allow them to sleep in the clinic. The district governor in Labaconas granted the local manager use of the municipal dirt bike to move more quickly between communities and did so free of charge. These and other relationships, all of which helped local managers implement Juntos, contributed to the creation of shadow conditions.

I will illustrate this with an example. In response to the failed agreements with the health and education sectors, local managers dutifully assumed responsibility for filling out the verification-of-coresponsibility forms, which Juntos used to monitor women's compliance with health and education conditions. While local managers understood that filling out the forms was up to them, they still relied on health and education staff to cooperate. In practice this meant that the health posts and clinics had to be open-while unexpected closures were not a problem at schools, they were persistently frustrating for local managers monitoring conditions at isolated health clinics. Local managers also needed staff to allow them access to medical histories and attendance records. At clinics, local managers relied on staff to help them locate medical histories that were missing or filed under a different village (which happened frequently), to provide information about pregnant women's expected due dates, and to navigate technical medical terminology. When local authorities at clinics and schools resisted helping, frustrated local managers had to manage the relationships carefully. On several occasions I observed local managers grinning through their teeth while confronting reticent health or school staff. Local managers described the situation pragmatically: "Well, in order to get the job done and get along, we don't grumble or say anything." Frontline program 
workers become adept at maintaining the social and organizational relationships upon which their work depends (Ahmad 2002), and Juntos local managers were no exception.

Relationships, of course, go two ways. Local authorities viewed the influence local managers had on Juntos mothers as advantageous to themselves and their own work responsibilities. School and health staff, local and regional government employees, politicians, NGO workers, and employees of other state social programs also made requests of local managers. They solicited women's time in health and development interventions, fairs, and parades, and they solicited women's financial resources for school supplies, for documents that should have been free of charge, and for fiestas. Local managers yielded to many of these demands, but not all of them. There was an "I'll scratch your back if you'll scratch mine" dynamic, but local managers decided on a case-by-case basis whether they'd participate. A local manager who decided a request was reasonable, or who needed a favor in return, could inform the mothers in his or her charge that Juntos required them to participate in or contribute to whatever activity was in question. Conditionality, as malleable as it was, was an important work tool.

Sometimes shadow conditions were created when local managers did not have the power to refuse a solicitation, even if they had wanted to. This was the result of institutional practices and processes that shaped how local managers accomplished their work. For instance, if health staff asked Juntos to prompt women to give birth at the clinic, and the local manager needed the health staff's support in order to monitor conditions, how could the manager refuse? If the difficult work of monitoring conditions in places with no public transportation was facilitated by use of the government dirt bike, and then the governor requested mothers' participation in his carnival parade, would the local manager say no? I will illustrate with another example.

One bright day in the capital of Santa Ana District, I was accompanying a local manager and a new local-manager-trainee as they monitored conditions. Juntos headquarters in Lima had recently imposed a new rule requiring local managers to obtain a signature from a local authority-for instance, a school director, mayor, or doctor-in order to prove that the local manager had been at work. ${ }^{19}$ The local manager and trainee decided to obtain the signature from the director of the elementary school. They had to visit the school anyway, because they needed the director to confirm that some children from Juntos households had graduated to the secondary school. My field notes from that day describe how a shadow condition developed in the interaction that ensued.

The director's office is bright and enormous, with shiny wooden floors that look as though they had just been waxed. There is an enormous desk that the director sits at. Straightaway, the director tells Lina that he has been having some problems. The mothers are protesting that they don't want to cook for the Qali Warma lunch program, so he told them that they must all contribute two and a half soles each so that 
they can hire a cook. The mothers are protesting this too, saying that they don't want to collaborate, and that the local manager told them they only have to "fulfill coresponsibilities in health and education." This upsets the director, because Qali Warma is a state program and there should be some "agreement" on this point-but there isn't any. Furthermore, he says, there is "too much paternalism."

The local manager agrees with this, saying, "[The women] want everything from heaven." She is being very sweet to him, negating having previously told the women that they should fulfill only health and education coresponsibilities. The director says he wants to make an announcement that Juntos gives the mothers money for health and education, and that the lunch is vitamins and minerals so they must collaborate. The local manager concurs with this, noting that "now the children eat good food" at school, better than at home. So she agrees with his proposal, saying, "Of course, make the announcement." The director then signed the local manager's and trainee's proof-of-work papers, and we left the office.

At the school office, the local manager and the school director negotiated the creation of a shadow condition. The negotiation underscored how easily the coercive power of incentives could be perverted, and how the poor mothers who relied on Juntos bore the costs. The local manager needed the director's signature to both complete her monitoring work and help Juntos monitor her. The director, who was responsible for implementing the state-funded lunch program, wanted the local manager to coerce the Juntos mothers, who were resisting his wishes, to "volunteer" their culinary labor.

The director made this request of the local manager because he recognized the coercive power of the cash incentive. The local manager had the option to collaborate with the director or to refuse. On other occasions I witnessed the same local manager refuse teachers who proposed that she tell Juntos mothers that they were required to contribute money from the Juntos payment for school parties. Local managers did not agree to with every illicit proposal. Unfortunately in the instance above, if the local manager had refused to comply with the director's request, he in turn could have refused to sign her papers, which would have put the local manager's job at risk. And the director's power was not limited to that one instance; in future, he could have restricted the local manager's access to the school and attendance records. The local manager's ultimate decision to comply with the director's demands was not justified, but it was understandable. He had power over her.

Anthropologist David Mosse found that when development practitioners in Bangladesh set out to implement policy, local relationships were of primary importance. "Viewed from an individual's perspective, project implementation is not only (or primarily) about executing policy, or even putting schemes in place, but a matter of sustaining a set of relationships that secure a person's identity and status, and which are a precondition for action at every level. Effective relationships are necessary to win support, sanction the flow of resources, build reputations, trust and reliability; to fend off arbitrary judgment" (Mosse 2005, 130). The importance 
of building and sustaining effective local relationships for the frontline state workers in charge of implementing Juntos was obvious. Yet in this negotiation of policy and power, the actors who were already the most marginalized were those who ended up losing the most: poor mothers. While the subject of the negotiation was the women's labor, the women themselves were not given a say. The mothers in question were not present in the office, and although they had voiced their preferences to the director at a previous time, he decided to dismiss their concerns.

Local managers and other authorities justified shadow conditions through rationalizations that associated poor mothers with free labor, and social support with the requirement to prove deservingness. While Qali Warma, like Juntos, was designed to improve children's health, the two programs did not have an agreement by which mothers cooked lunches on account of their status as Juntos recipients. Nevertheless, the director rationalized his request on the basis of the nutritional benefits that Qali Warma provided to Juntos recipients' children. Cooking for the lunch program was the responsible thing for mothers to do. It was possible that the local manager rationalized the arrangement through a similar logic. When I interviewed her, she told me that she often spoke to mothers about what and how often they should feed their children. She believed that nutrition was central to a family's capacity to overcome their poverty.

By many accounts, Qali Warma was a good program-it provided students in rural Peru with nutritious meals that were often made with local ingredients, at no charge. Yet in order to do so, it relied on the unpaid labor of mothers. In this, Qali Warma was not unlike many other social programs throughout Peru's history that have provided goods and services through women's unpaid care work (Barrig 1991; Blondet and Trivelli 2004; Rousseau 2009). From the perspective of the director, why not use one social program to help another? And what was the problem with making sure that lazy, entitled women properly fed their children? When mothers in Santa Ana resisted the exploitation of their labor, the school director capitalized on the opportunity to use Juntos to bring them into line.

Shadow conditions draw our attention to the coercive power of incentives and the multiple possibilities for their perversion. On paper, conditional aid seems like a tidy technical mechanism for helping families improve their lives. In the real world of bodies, uneven development, and inequality, conditionality became a tool for more powerful groups to implement their own projects of improvement among less powerful groups. Authorities within and outside of Juntos used the program to discipline women's behavior, either for their own professional benefit or in order to achieve an end that they believed to be benevolent. If the governor believes that his political party's plan for regional development will help families overcome poverty, why not incentivize them to show support in the local parade? If the foreign volunteer corps believes that women need access to the market in order to overcome poverty, why not incentivize them to weave colored belts for sale in tourist centers? If the local manager believes that the women he manages 
must have fewer children in order to overcome poverty, why not incentivize them to use contraceptives?

Shadow conditions were not simply the well-intended distractions that experts in Lima supposed. Rather, shadow conditions were an integral feature of program implementation. Juntos was unviable unless local managers succeeded in getting school and health clinic authorities, among others, to assist them in tracking beneficiaries, filling out coresponsibility forms, and facilitating travel and accommodation. Local managers stretched the boundaries of what could and could not be made conditional in order to produce and obtain the data that Juntos required. The limits on this top-down power were unclear.

\section{CONCLUSION}

Global development experts claim that CCTs are important components of the global "safety net" (Fiszbein et al. 2009; World Bank 2017). Yet the experiences of Peruvian mothers who rely on conditional aid undercut this claim. Juntos mother Josepa captured this idea: "Well, it frightens me. I say to myself, 'Are they going to take [the transfer] away from me if I don't bring [my son] to the day care?" 'With reason, a safety net feels less safe when rendered insecure by threats of local managers and other authorities.

Burdening poor women with microproductive projects while failing to address infrastructural barriers that complicate basic care work is unjust; conditioning poor women's access to social protection upon their ability to grow leafy greens is even more so. It would also be misguided to blame the local managers who used threats of suspension and shadow conditions to get their work done. While their abuses of power were undeniably wrong, these must be viewed within the broader context of uneven development, the difficulty of the tasks policy makers assigned them and their own precarious social position-only one or two rungs above the households they manage.

Technical interventions, of which the CCT is exemplary, can produce a host of unintended consequences when they fail to grapple with the messy social, economic, and political issues driving persistent inequities. Conditionality is a tidy arrangement curated and packaged in air-conditioned offices located far away from the impoverished communities, households, and bodies it is used to improve. Good intentions notwithstanding, Juntos mutated with ease. It quickly unraveled and became unruly in the real world, where economic policies, sexist assumptions, discriminatory attitudes, and uneven investments accord some people more power than others. As a result, poor rural mothers did not encounter a simple incentive program - they encountered shadow conditions and seemingly limitless demands on their time and labor. If the costs of conditionality remain in the shadows of the global policy landscape, they certainly were not hidden from these women. 